\title{
Overexpression of KiSS-1 reduces colorectal cancer cell invasion by downregulating MMP-9 via blocking PI3K/Akt/NF-kB signal pathway
}

\author{
SHAOQIN CHEN, WEI CHEN, XIANG ZHANG, SUYONG LIN and ZHIHUA CHEN \\ Department of Gastrointestinal Surgery, The First Affiliated Hospital \\ of Fujian Medical University, Fuzhou, Fujian 350005, P.R. China
}

Received November 25, 2015; Accepted December 31, 2015

DOI: $10.3892 /$ ijo.2016.3368

\begin{abstract}
Metastasis of colorectal cancer (CRC) depends critically on MMP-9. KiSS-1 is a human malignant melanoma metastasis-suppressor gene. Thus, the interaction between MMP-9 and KiSS-1 has drawn considerable attention in recent years. In the present study, it was hypothesized that KiSS-I gene could repress the metastatic potential of colorectal cancer cells by inhibiting the expression of MMP-9. Stable transfection of KiSS-1 specific siRNA and KiSS-1 expression vector in human CRC cell line HCT-116 was achieved by lentivirus infection. Moreover, the cell proliferation, invasiveness, and apoptosis were evaluated by CCK-8 method, transwell experiment, and fluorescence activated cell sorter, respectively. We also investigated the expression of MMP-9, PI3K, Akt, pAKt, and NF-KB subunit p65 using western blotting. KiSS-1 overexpression significantly decreased the cell proliferation and invasiveness of HCT-119 cells, while apoptosis was enhanced. The result of western blotting showed that synthesis of MMP-9, PI3K, p65, and phosphorylation of Akt were significantly blocked by overexpression of KiSS-1. Concatenated treatment of KiSS-1 overexpression vector with PI3K and Akt agonists attenuated the effect of KiSS-1 on the biological activity of CRC cells and also released the expression of MMP-9, PI3K, p65, and phosphorylation of Akt from the influence of overexpression of KiSS-1. Overexpression of KiSS-1 suppressed the invasiveness of CRC cells, and the gene exerted its function by reducing the expression of MMP-9 via blocking of tge PI3K/ Akt/NF-kB pathway.
\end{abstract}

Correspondence to: Dr Shaoqin Chen, Department of Gastrointestinal Surgery, The First Affiliated Hospital of Fujian Medical University, 20 Chazhong Road, Fuzhou, Fujian 350005, P.R. China E-mail: chenshaoqin1613@163.com

Key words: KiSS-1, colorectal cancer, metastasis, matrix metalloprotease, $\mathrm{PI} 3 \mathrm{~K}, \mathrm{Akt}, \mathrm{NF}-\mathrm{\kappa B}$

\section{Introduction}

Colorectal cancer (CRC) ranks the third most common cancer of all cancer types and is a major public health problem. In 2000, more than 1.2 million people were diagnosed with CRC (1), and according to the latest investigation in 2014, $\mathrm{CRC}$ is responsible for $8-9 \%$ of the cancer-related deaths in the USA (2). However, the incidence of CRC varies with geography with the incidence rate in the USA and Europe being 10 -fold higher than in African and Asian countries. CRC is quite a complex disease and tumors with similar histopathological characteristics will finally develop with variable course in response to different treatments (3). As with all types of tumors, CRC is now proved to be a chronic systemic disease: neoplastic cells develop at tumor sites first and then metastasize to other parts of the body (4). Fortunately, advances in molecular biology in the last decades have facilitated the elucidation of some of the genetic mechanisms involved in the oncogenesis and development of CRC.

Three major mechanisms that cause aberrant gene expression results in the carcinogenesis of the colon: microsatellite instability (MSI), chromosomal instability (CIN), and the $\mathrm{CpG}$ island methylator phenotype (CIMP). These processes lead to the transition in lesion pathology and progression to malignancy, which is accompanied by downregulated expression of tumor suppression genes. Vogelstein et al have inferred that the accumulation of genetic alterations, in particular APC, TP53, and KRAS mutation is responsible for CRC development (5). Moreover, increased activity of matrix metalloprotease-9 (MMP-9) was also detected in plasma of patients with colon cancer (6,7). MMP-9 is a matrix metalloproteinase, which is closely related multi-gene family of zinc-dependent proteolytic enzymes. It plays a role in normal physiological tissue remodeling and is capable of degrading all components of the extracellular matrix. Increasing evidence has proved the important contribution of MMP-9 to CRC $(8,9)$, other studies have already revealed the underlying molecular mechanism involved in MMP-9 inducing cancer cell invasion (10). Taken the above information together, it is reasonable to consider MMP-9 as a potential therapeutic target for treatment of CRC.

A great deal of genes associated with metastases of cancer has been identified in the last decades. One of these genes 
is $K i S S$ - 1 , expression of which is reported to be reduced in metastatic cancer (11). Moreover, its ability to suppress the metastatic potential of breast cancer cells without affecting tumorigenicity was also verified $(11,12)$. Since MMP-9 has well-established role in tumor cell invasion and metastases, the interaction between MMP-9 and KiSS-1 has already drawn attention and the inhibition effect of KiSS-1 on the expression of MMP-9 has been validated (10). However, to the best of our knowledge, the mechanism by which KiSS-1 regulates MMP-9 and suppresses the metastatic phenotype remains partially explored, especially in CRC, the related studies are scarce.

Thus, in the present study, we hypothesized that KiSS-1 gene could repress the metastatic potential of colorectal cancer cells by downregulating the expression of MMP-9. Based on previous studies (10), we also investigated the possible molecular mechanism participating in these processes. Stable regulation of KiSS-1 gene in HCT-116 cells was achieved by lentivirus infection method. The effect of KiSS-1 on the cell viability, migration, and apoptosis was determined. The possible pathway involved in these processes was also evaluated by western blotting. Our aim was to assess the role of KiSS- 1 and whether it was involved in oncogenesis and development of CRC to and facilitate the prevention and treatment of $\mathrm{CRC}$ in the clinic.

\section{Materials and methods}

Cell cultures and chemicals. Human CRC cell line HCT-116 was purchased from American Type Culture Collection (ATCC) (Rockville, MD, USA) and cultured in DMEM/F-12 medium supplemented with $10 \%$ (v/v) fetal calf serum (Gibco Life Technologies, Carlsbad, CA, USA) and 1\% (v/v) antibiotics mixture in $95 \%$ air and $5 \% \mathrm{CO}_{2}$ at $37^{\circ} \mathrm{C}$. In addition, cells between passage 3 and 6 were used for further experiments. PI3K/Akt pathway agonist 740Y-P and PDGF were purchased from Sigma-Aldrich, St. Louis, MO, USA.

siRNA interference of the KiSS-1 gene. Lentivirus-mediated KiSS-1-specific siRNA (5'-GCCGAACUACAACUGGA ACTT-3') and the negative control siRNA (NC) were obtained from Genechem Biotech (Shanghai, China). The most effective transfection concentration of lentivirus was determined by multiplicity of infection (MOI). Based on the results (data not shown), lentivirus concentration at MOI $100\left(10 \mu 11 \times 10^{8}\right.$ $\mathrm{TU} / \mathrm{ml}$ lentivirus $+90 \mu \mathrm{l}$ medium) was chosen for further experiments.

The cell concentration of HCT-116 was adjusted to $1 \times 10^{4} / \mathrm{ml}$ and incubated on slides in one well of 24-well plates for 24 h. Transfection was performed with Lipofectamine 2000 reagent (Invitrogen) according to the manufacturer's protocol and subsequent selection was conducted using $400-\mu \mathrm{g} / \mathrm{ml}$ puromycin (Amresco, Solon, OH, USA). HCT-116 cells were grouped into two treatments: i) NC-siRNA group, HCT-116 cells were transfected with negative control siRNA. ii) KiSS-1-siRNA group, HCT-116 cells were transfected with KiSS-1-specific siRNA. Each treatment consisted of six replicates. All the cells were cultured for $96 \mathrm{~h}$ and cell sampling was conducted every $24 \mathrm{~h}$ during the experimental course from $0 \mathrm{~h}$.
Overexpression of KiSS-1 gene in HCT-116 cells. Lentivirusmediated KiSS-1 vector and negative control vector were purchased from Genechem (Shanghai, China). The most effective transfection concentration of lentivirus was determined by multiplicity of infection (MOI). Based on the results (data not shown), lentivirus concentration at MOI $100\left(10 \mu 11 \times 10^{8}\right.$ $\mathrm{TU} / \mathrm{ml}$ lentivirus $+90 \mu \mathrm{l}$ medium) was chosen for further experiments. HCT-116 cells were grouped into two treatments and transfection was conducted as described above: i) control group, HCT-116 cells transfected with negative control vector. ii) KiSS-1 group, HCT-116 cells transfected with KiSS-1 vector. Each treatment consisted of six replicates. Cells were cultured for $96 \mathrm{~h}$ and sampling was conducted at 24, 48, 72, and $96 \mathrm{~h}$.

Quantitative real-time PCR ( $q P C R)$. For cell cultures from $24 \mathrm{~h}$ in different treatments, the whole RNA was extracted using TRIzol method according to the manufacturer's instructions. In addition, NAPDH was selected as the reference gene. The RNA was reverse transcribed to cDNA using RT-PCR kit (Fermentas China Co., Ltd., Shenzhen, China), and the final reaction mixture of volume $20 \mu \mathrm{l}$ contained $10 \mu \mathrm{l}$ of SYS BR Primix Ex Taq 2, $0.5 \mu 1$ of each primers (KiSS-1, forward: 5'-AGCCGCCAGATCCCCGCA-3'; reverse: 5'-GCCGAA GGAGTTCCAGTTGTAGTT-3'. GAPDH, forward: 5'-GGG TGGAGCCAAACGGGTC-3'; reverse: 5'-GGAGTTGC TGTTGAAGTCGCA-3'), $1 \mu$ l of the cDNA template, and $8 \mu 1$ $\mathrm{ddH}_{2} \mathrm{O}$. Thermal cycling parameters for the amplification were as follows: a denaturation step at $94^{\circ} \mathrm{C}$ for $2 \mathrm{~min}$, followed by 40 cycles at $94^{\circ} \mathrm{C}$ for $20 \mathrm{sec}, 58^{\circ} \mathrm{C}$ for $30 \mathrm{sec}$ and $72^{\circ} \mathrm{C}$ for $20 \mathrm{sec}$. Relative gene expression was evaluated with Data Assist software version 3.0 (Applied Biosystems, Foster City, CA, USA). The relative expression levels of $K i S S-1$ were determined according to the expression of $2^{-\Delta \Delta c t}$.

Western blot assay. Concentrations of protein samples were determined using the BCA method and western blot assay was performed as previously described (13); $20 \mu \mathrm{g}$ of protein was subject to a $10 \%$ sodium dodecylsulfate polyacrylamide gel electrophoresis (SDS-PAGE). Then targeted proteins were transferred onto polyvinylidene difluoride (PVDF) sheets. The membranes were washed with TBST for $5 \mathrm{~min}$ and then transferred into blocking buffer for incubation overnight at $4^{\circ} \mathrm{C}$. After three cycles of $5 \mathrm{~min}$ washes with TBST, primary antibodies (1:2000) against KiSS-1 or GAPDH were incubated with the membranes for $1 \mathrm{~h}$ at room temperature. After additional three washes, secondary HRP goat anti-rabbit IgG antibodies (1:2000) were added and incubated with the membranes for $40 \mathrm{~min}$. After final three washes using TBST, the blots were developed using Beyo ECL Plus reagent and the results were detected in the Gel Imaging System. The relative expression levels of different proteins were calculated with Bio-Rad Quantity One.

Cell proliferation assay. For cell samples from 24, 48, 72, $96 \mathrm{~h}$ in both KiSS-1 interference and KiSS-1 overexpression treatments, cell viabilities were measured by CCK-8 method: briefly, CCK- 8 solution was added to cells at different time points and cultured at $37^{\circ} \mathrm{C}$ for $90 \mathrm{~min}$. OD value at $450 \mathrm{~nm}$ was determined using a Microplate Reader. 

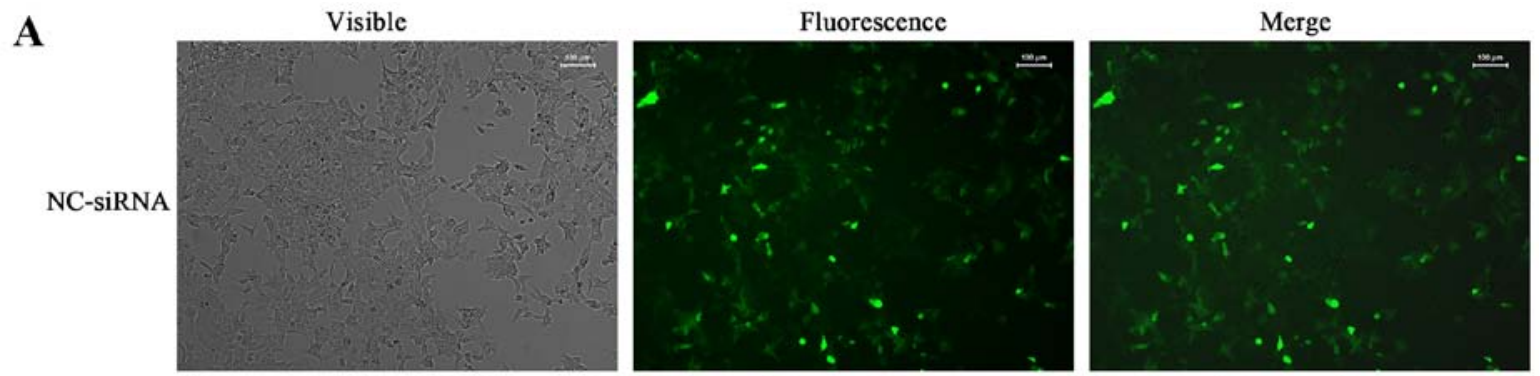

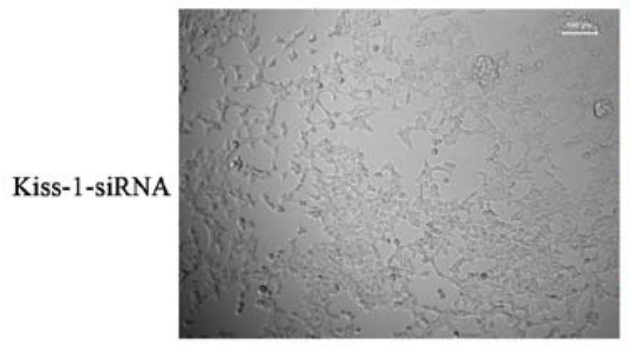

B

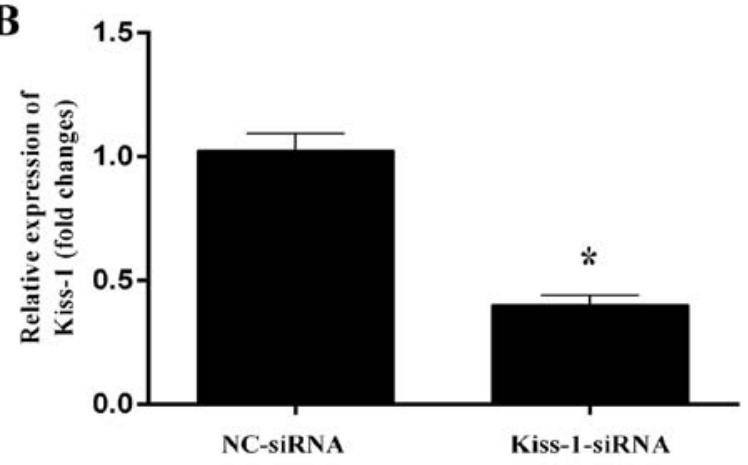

C
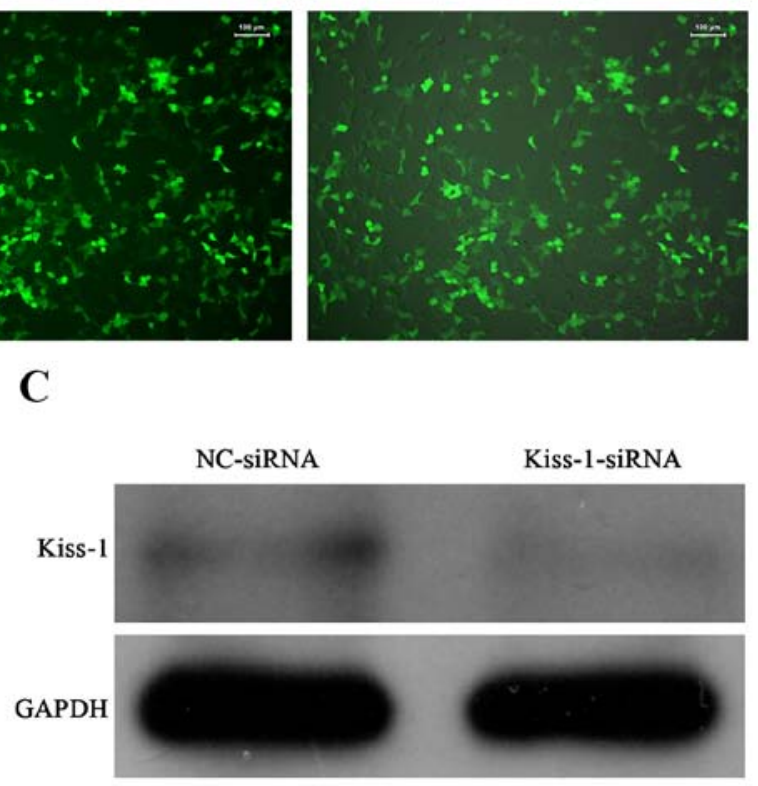

Figure 1. Expression of KiSS-1 after KiSS-1-specific siRNA transfection. (A) Stable transfection was achieved with lentivirus infection, MOI = 100. (B) Illustration of qPCR after $K i S S$-1-specific siRNA transfection. (C) Illustration of western blot $K i S S$-1-specific siRNA transfection. Significantly different from control group, ${ }^{*} \mathrm{P}<0.05$.

Transwell invasion assay. The transwell experiment to evaluate the invasion ability of HCT-116 cells was performed in cell samples from $96 \mathrm{~h}$ in different treatments: $100 \mu \mathrm{l}$ of incubation medium (with $1 \mathrm{mM} \mathrm{MgCl}$ ) containing $1 \times 10^{5}$ cells were seeded into the upper chamber of BSA coated $8 \mu \mathrm{M}$ pore size transwell chambers (Corning Star, Cambridge, MA, USA). Then cells were incubated at $37^{\circ} \mathrm{C}$ for $4 \mathrm{~h}$ to allow the migration through the porous membrane. The cells remaining at the upper surface of the chamber were completely removed. The lower surfaces of the membranes were stained in a solution containing $1 \%(\mathrm{w} / \mathrm{v})$ crystal violet in $2 \%$ ethanol for $30 \mathrm{sec}$ and then washed with $\mathrm{ddH}_{2} \mathrm{O}$. Extraction of cell-associated crystal violet was performed by incubating in $10 \%$ acetic acid for 20 min. Results were observed using an Olympus CX41 microscope and the cell number in different treatments was determined using Image-Pro Plus 6.0 software (Nikon).

Fluorescence activated cell sorter. Effect of regulation of KiSS-1 gene on the apoptosis in HCT-116 cells was also determined using fluorescence activated cell sorter (FACS): $200 \mu 1$ Annexin V/7-ADD working solution (5 $\mu$ l Annexin V and $10 \mu \mathrm{l}$ 7-AAD in $0.5 \mathrm{ml} 1 \mathrm{X}$ Binding buffer) was added to cell samples from $96 \mathrm{~h}$ in different treatments. After incubation for $15 \mathrm{~min}$ at room temperature in the dark, the apoptotic rate was detected with flow cytometry. Each treatment was represented by three replicates. Apoptotic rate (UR+LR-all apoptosis cell percentage) was equal to the sum of the cell death rate (UR, upper right quadrant-advanced stage apoptosis cell percentage) and the early apoptosis rate (LR, lower right quadrant-prophase apoptosis cell percentage).

Detection of inhibition of KiSS-1 gene on PI3K/Akt/NF- $\mathrm{BB}$ mediated MMP-9 expression. To further determine the molecular mechanism of KiSS-1 gene reducing the expression of MMP-9, we assessed the effect of KiSS-1 gene overexpression on $\mathrm{PI} 3 \mathrm{~K} / \mathrm{Akt} / \mathrm{NF}-\kappa \mathrm{B}$ signal transduction pathway. HCT-116 cells were classified into 4 groups: i) NC group, HCT-116 cells transfected with negative control lentivirus vector. ii) KiSS-1 group, HCT-116 cells transfected with lentivirus-mediated KiSS-1 vector. iii) KiSS-1 + 740Y-P group, KiSS-1 overexpression HCT-116 cells incubated with PI3K agonist 740Y-P (50 $\mu \mathrm{g} / \mathrm{ml})$ for $90 \mathrm{~min}$. iv) KiSS-1 + PDGF group, KiSS-1 overexpression HCT-116 cells incubated with Akt agonist PDGF (100 ng/ml) for $1 \mathrm{~h}$. Each treatment consisted of six replicates. All the cells were cultured for $96 \mathrm{~h}$ and sampled every $24 \mathrm{~h}$. Cell viabilities of cultures from time points $24,48,72$, and $96 \mathrm{~h}$ were measured using CCK-8 method as described above. In addition, cell invasion ability and apoptotic rate were determined using cell samples from $96 \mathrm{~h}$. The expression of PI3K, Akt, pAkt, NF- $\mathrm{B}$ subunit p65, and MMP-9 was determined with western blotting as described above. 
A
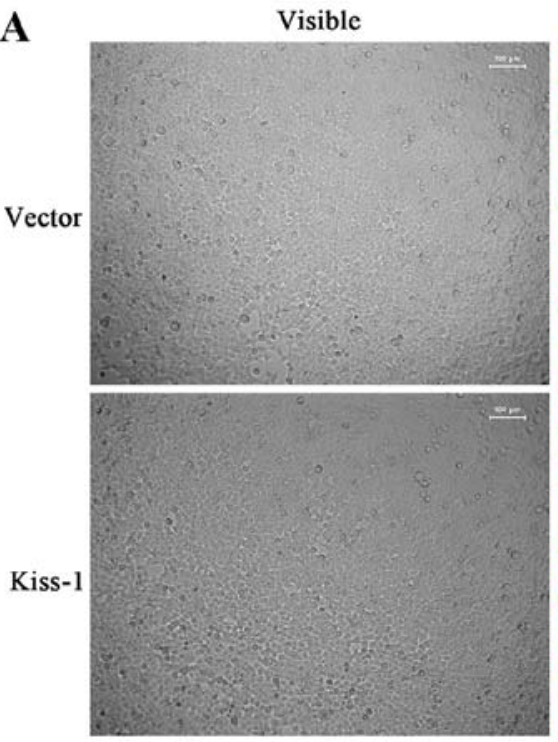

B

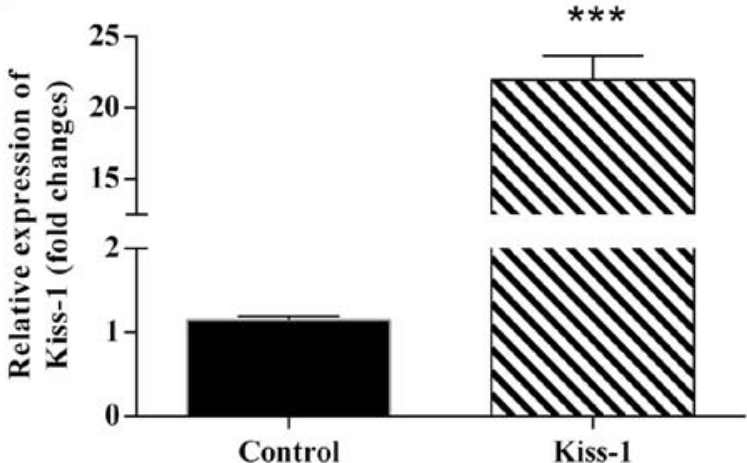

Kiss-1
Fluorescence
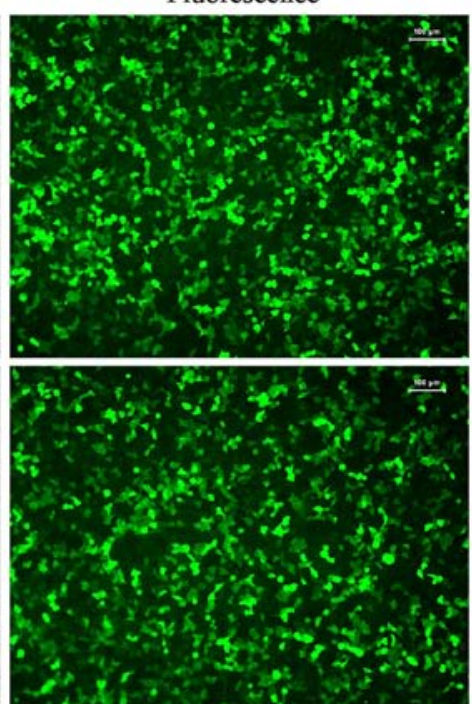
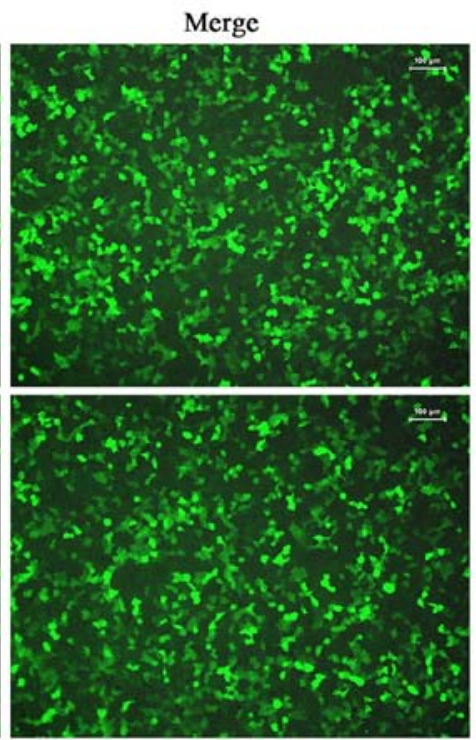

C

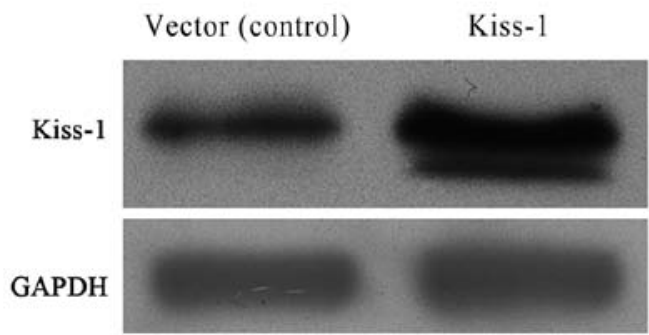

Figure 2. Expression of KiSS-1 after KiSS-1 vector transfection. (A) Stable transfection was achieved with lentivirus infection, MOI=100. (B) Illustration of qPCR after KiSS-1 vector transfection. (C) Illustration of western blot after KiSS-1 vector transfection. Significantly different from control group, ${ }^{* * *} \mathrm{P}<0.001$.

Statistical analysis. The data are expressed as the mean \pm SD. Student t-test and multiple comparisons with LSD method were conducted by using GLM model with significant level of $\mathrm{p}<0.05$. All the statistical analysis were conducted using SPSS version 19.0 (IBM, Armonk, NY, USA).

\section{Results}

Stable regulation of KiSS-1 gene in HCT-116 cells. Stable transfection of KiSS-1-specific siRNA and lentivirus-mediated KiSS- 1 vector was detected using qPCR and western blotting (Figs. 1 and 2). The transfection of KiSS-1-specific siRNA significantly downregulated the transcription and synthesis of KiSS-1 (Fig. 1B and C), and the transfection of KiSS-1 vector significantly upregulated the expression of KiSS-1 in both mRNA and protein levels (Fig. 2B and C).

Silencing of KiSS-1 gene by KiSS-1-specific siRNA has no impact on the cell viability, cell apoptosis, and invasion ability in HCT-116 cells. Although transfection with KiSS-1-specific siRNA influenced the transcription and production of KiSS-1, it seemed that silencing of KiSS-1 gene had no influence on the on the cell viability, cell invasion ability, or apoptosis within our experimental period (Figs. 3 and 4), which might indicate that the expression of KiSS-1 gene in normal HCT-116 cells was low and inhibition of the transcription of KiSS- 1 gene had little influence on the regular biological activity of CRC cells.

Overexpression of KiSS-1 gene reduces the cell viability while induces cell apoptosis in HCT-116 cells. Overexpression of KiSS-1 gene led to a significant decrease in the cell proliferation in HCT-116 cells, especially at sampling points of 72 and $96 \mathrm{~h}$, showing the potential of KiSS-1 as an effective anti-tumor target (Fig. 5A). Similar results were also observed in FACS, overexpression of KiSS-1 significantly increased the apoptotic rate (24.0\%) in KiSS-1 group compared with NC group (7.1\%) (Fig. 5B and C). Moreover, most non-viable cells in KiSS-1 group belonged to early apoptosis stage (18.9\%).

Overexpression of KiSS-1 gene decreases invasion ability in HCT-116 cells. The cell migration ability was evidently influenced by overexpression of KiSS-1 gene. To assess the function of KiSS-1 on cell mobility, we performed migration experiments in a modified Boyden chamber with HCT-116 cell transfected with different categories. Overexpression of KiSS-1 strongly reduced cell migration in KiSS-1 group (Fig. 6), however, given that the silencing of KiSS-1 had no significant effect on cell migration (Fig. 4), we inferred that KiSS-1 might exert its function in metastasis of CRC cells in an indirect manner. 
A

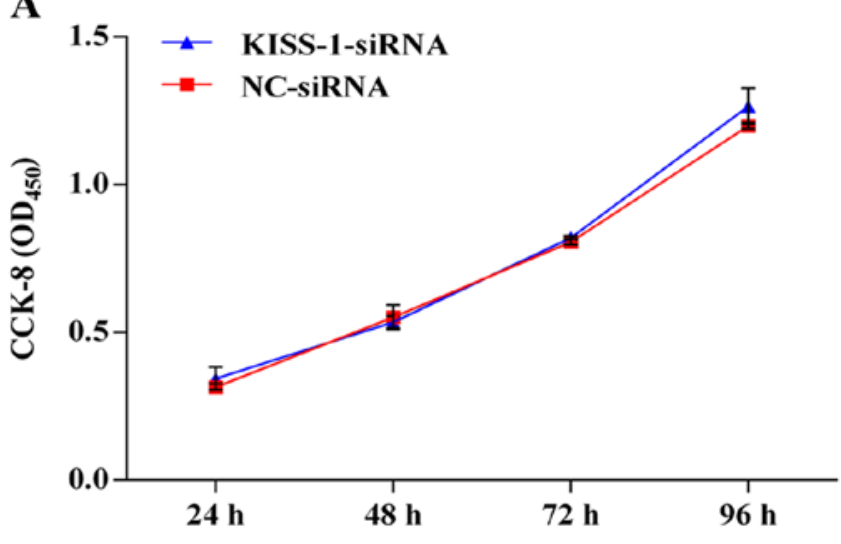

B
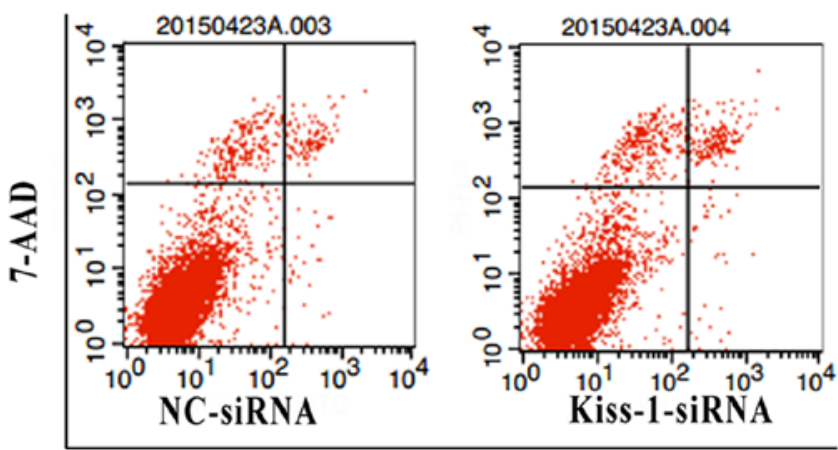

Annexin V-APC

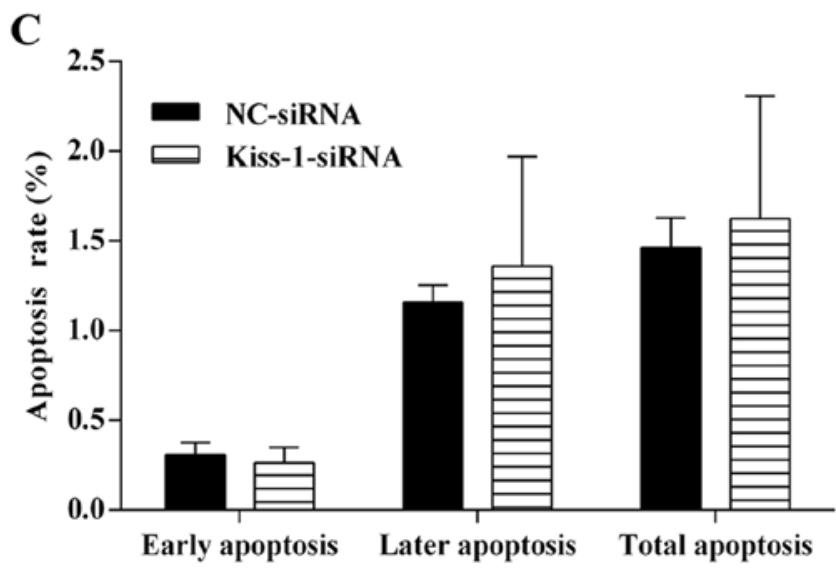

Figure 3. Effect of KiSS-1-specific siRNA transfection on the cell proliferation and apoptosis of HCT-119 cells. (A) Influence of KiSS-1-specific siRNA transfection on the cell viability. (B) Influence of KiSS-1-specific siRNA transfection on the cell apoptosis. (C) Percentage of apoptotic cells evaluated by FACS.

Employment of PI3K/Akt agonists attenuate the effect of KiSS-1 on the cell viability, cell apoptosis, and invasion ability in HCT-116 cells. To further explore the mechanism of KiSS-1 influencing the expression of MMP-9 and then reducing the metastasis of CRC cells, we set up another two groups, KiSS-1 overexpression HCT-116 cells incubated with PI3K agonist 740Y-P and Akt agonist PDGF, respectively. Treatments with the agonists significantly reversed the damage to HCT-116 cells. The cell viability in KiSS-1 + 740Y-P group and KiSS-1 + PDGF group was much higher than that in KiSS-1 group (Fig. 7A). The apoptotic rate and migration ability were also improved by incubation with the agonists (Figs. 7B and C,

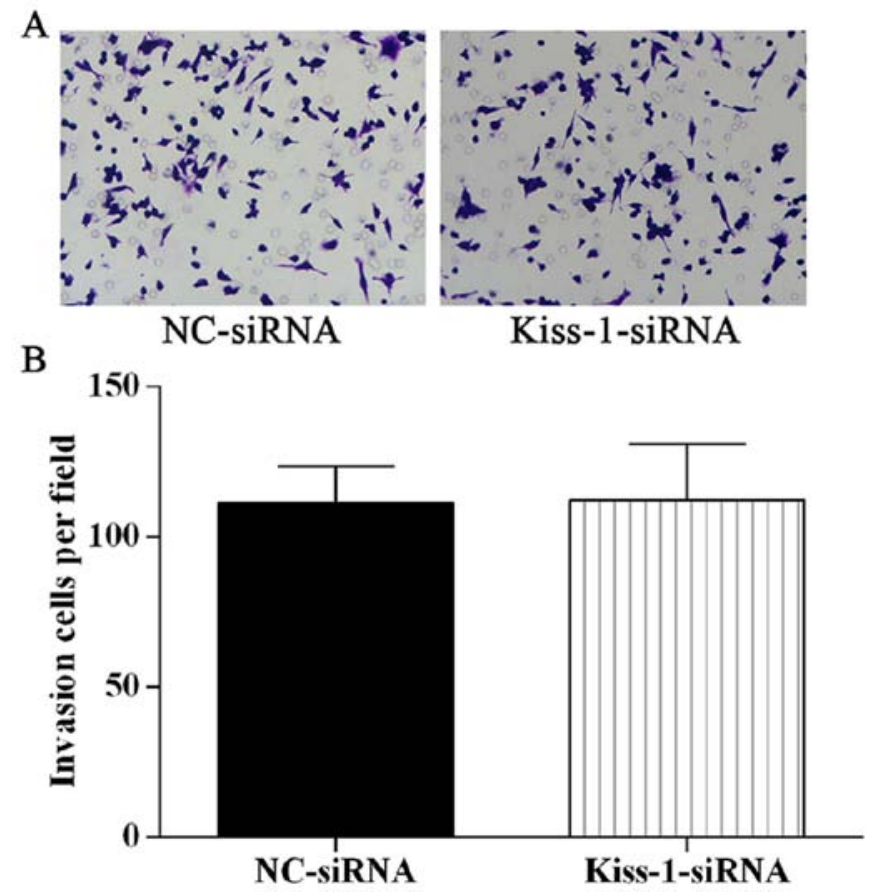

Figure 4. Effect of KiSS-1-specific siRNA transfection on the invasion of HCT-119 cells. (A) The graph represents invasion ability of HCT-119 cells detected by transwell experiment. (B) Influence of KiSS-1 specific siRNA transfection on the invasion ability of HCT-119 cells.

and 8). Although the biological condition of cells in these two groups was still poorer than NC group, the results indicated the evident involvement of PI3K/Akt pathway in KiSS-1 reducing proliferation and migration ability of HCT-116 cells.

KiSS-1 downregulates the expression of MMP-9 by blocking $P I 3 K / A k t / N F-\kappa B$ pathway. We investigated the effect of KiSS-1 overexpression on the downstream activation by detecting the synthesis of MMP-9, PI3K, p65 and phosphorylation of Akt. Furthermore, to activate these pathways, we also treated KiSS-1 overexpression HCT-116 cells with PI3K/Akt agonists 740Y-P and PDGF. The results of western blotting clearly showed that the transfection with lentivirus-mediated KiSS-1 vector significantly reduced the synthesis of MMP-9, PI3K, pAkt, and p65 (Fig. 9). By co-incubation with different agonists, KiSS-1 overexpression-induced inhibition could be attenuated (Fig. 9). Taken the above information together, our results demonstrated that the decrease in cell invasion in CRC cells might result from the inhibition of MMP-9 due to KiSS- 1 blocking the PI3K/Akt/ $\mathrm{NF}-\kappa \mathrm{B}$ signal transduction pathway.

\section{Discussion}

As proposed by Fearon and Vogelstein (14), CRC is a type of malignant neoplasm resulted from acquired and/or innate molecular alterations in colonic mucosa. Consumption of red meat and alcohol as well as obesity is associated with a higher risk of CRC. Moreover, inflammatory bowel patients also have greater risk for CRC development than health people. The genetic mutations and expression patterns of molecular markers involved in the oncogenesis of CRC and the in CRC are variable (15-17), which has led scientists to explore further 

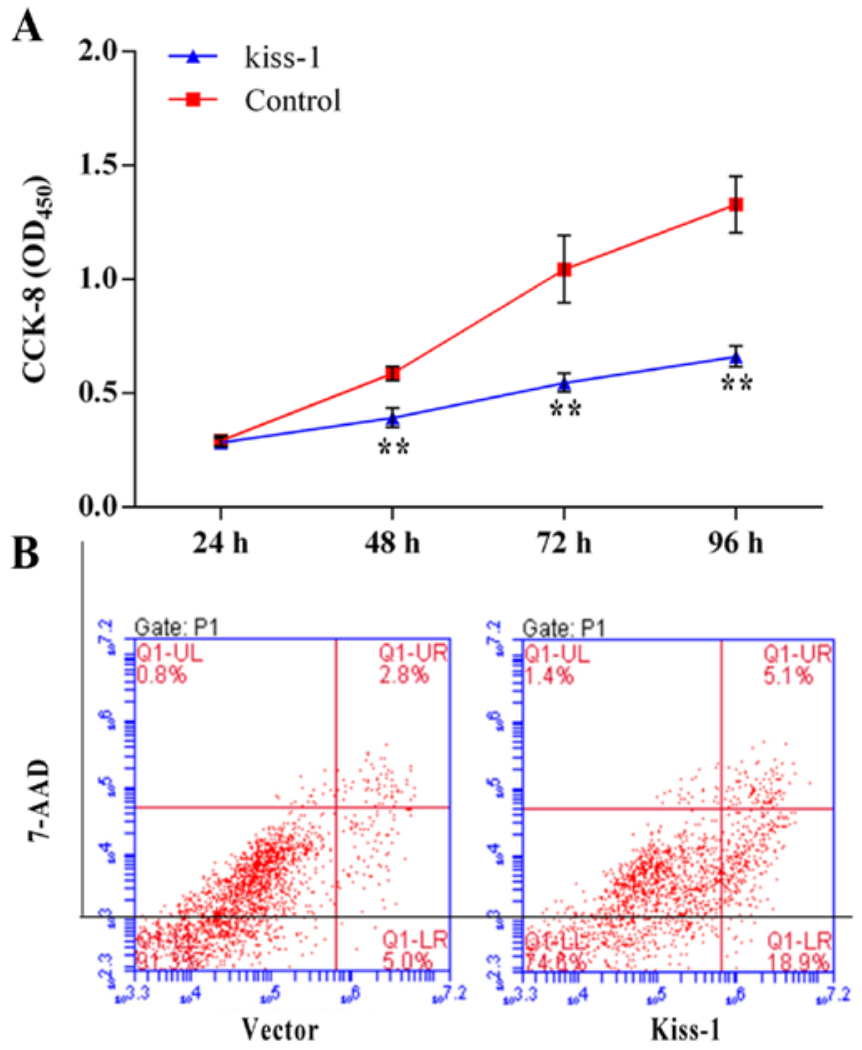

C

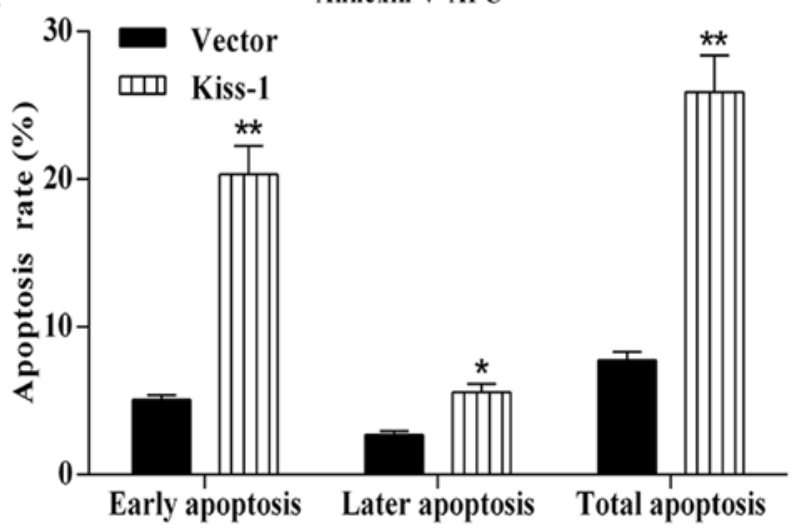

Figure 5. Effect of KiSS-1 vector transfection on the cell proliferation and apoptosis of HCT-119 cells. (A) Influence of KiSS-1 vector transfection on the cell viability. (B) Influence of KiSS-1 vector transfection on cell apoptosis. (C) Percentage of apoptotic cells evaluated by FACS. Significantly different from control group, ${ }^{*} \mathrm{P}<0.05$. Significantly different from control group, ${ }^{* * *} \mathrm{P}<0.01$.

the molecular level to meet the need for an accurate diagnosis, prognosis, and efficient therapeutic approach for CRC.

Cancer invasion and metastasis depend critically on the degradation of the extracellular matrix surrounding the tumor tissues. The process is believed to be activated by the action of proteolytic enzymes, including several types of MMPs (18). In the case of CRC, most studies have reported the increased expression of MMP-9 in patients with gastrointestinal cancers (8). Thus, regulation of MMP-9 has become a novel therapeutic target for prevention and treatment of CRC $(8,9)$. Previous study of Yan et al (19) showed that KiSS-1 could repress MMP-9 in the human sarcoma cell line HT-1080, however, few studies have paid attention to the role of KiSS-1

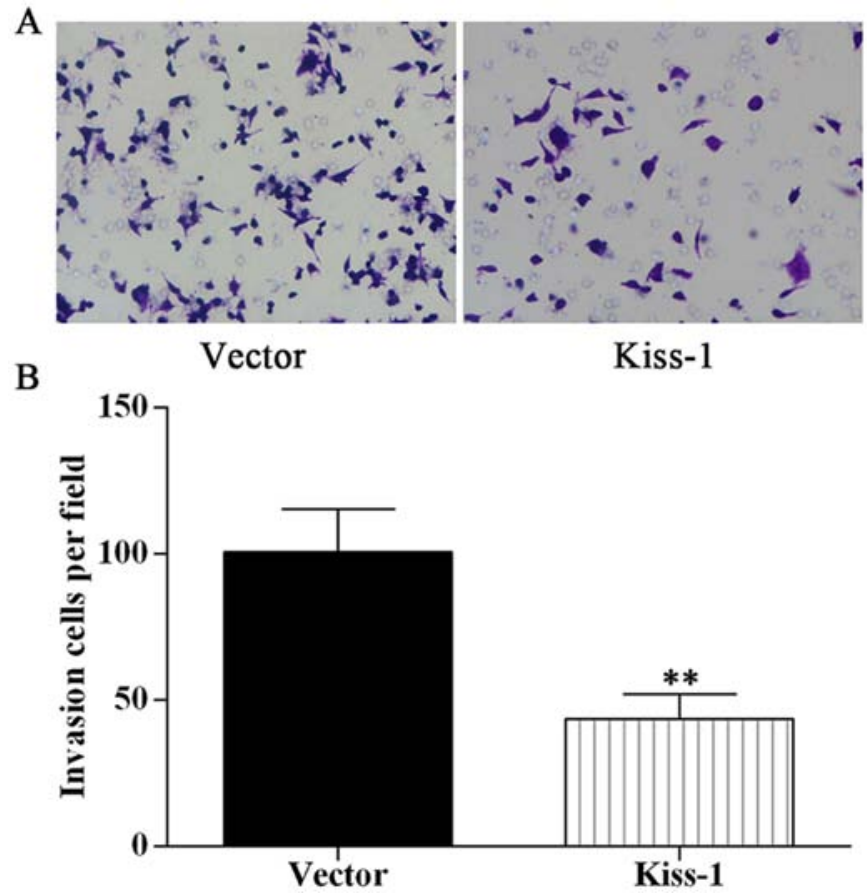

Figure 6. Effect of KiSS-1 vector transfection on the invasion of HCT-119 cells. (A) The graph represents invasion ability of HCT-119 cells detected by transwell experiments. (B) Influence of $K i S S-1$ vector transfection on the invasion ability of HCT-119 cells. ${ }^{* *} \mathrm{P}<0.01$

in regulating MMP-9 in CRC, neither the related mechanisms. In the present study, we demonstrated that KiSS-1 gene could reduce the metastatic potential of colorectal cancer cells by downregulating the expression of MMP-9 and the interaction between KiSS-1 and MMP-9 was connected through the PI3K/ $\mathrm{Akt} / \mathrm{NF}-\kappa \mathrm{B}$ signal transduction pathway.

Our data elucidated that overexpression of KiSS-1 gene significantly suppressed the invasiveness and proliferation of in human CRC cell line HCT-116 while cell apoptosis was enhanced. Potential of migration and invasion is critical for tumor progression and metastasis. Lee and colleague have indicated that KiSS-1 inhibits invasiveness and metastasis of cancer cells (11). They found that loss of expression of KiSS-1 correlated with metastatic potential in human melanoma cells. This finding implies the therapeutic effect of KiSS-1 to reduce the migration ability of tumor cells. Our data derived from CRC model was different from that of the study by Lee et al (11): it was found that the silencing of KiSS-1 by specific siRNA had no influence on the cell viability, invasion, and apoptosis, although the transcription and synthesis of KiSS-1 in our experiment were significantly downregulated by RNAi technique. However, overexpression of KiSS-1 led to a significant decrease in cell invasion and proliferation. Thus, the regulation of KiSS-1 on the metastatic phenotype of different tumors is more complicated than expected.

Exposure to overexpression of KiSS-1 may induce the alteration of cellular signaling pathway mediators involved in the invasion of tumor cells, such as PI3K, MAPK, JNK, Akt, and NF- $\kappa \mathrm{B}(10,20,21)$. However, previous studies showed that PI3K/Akt was one of the signal pathways to induce MMP-9 secretion and expression of $K i S S-1$ could reduce the $\mathrm{NF}-\kappa \mathrm{B}$ binding to the MMP-9 promoter $(19,22)$. To elucidate the 

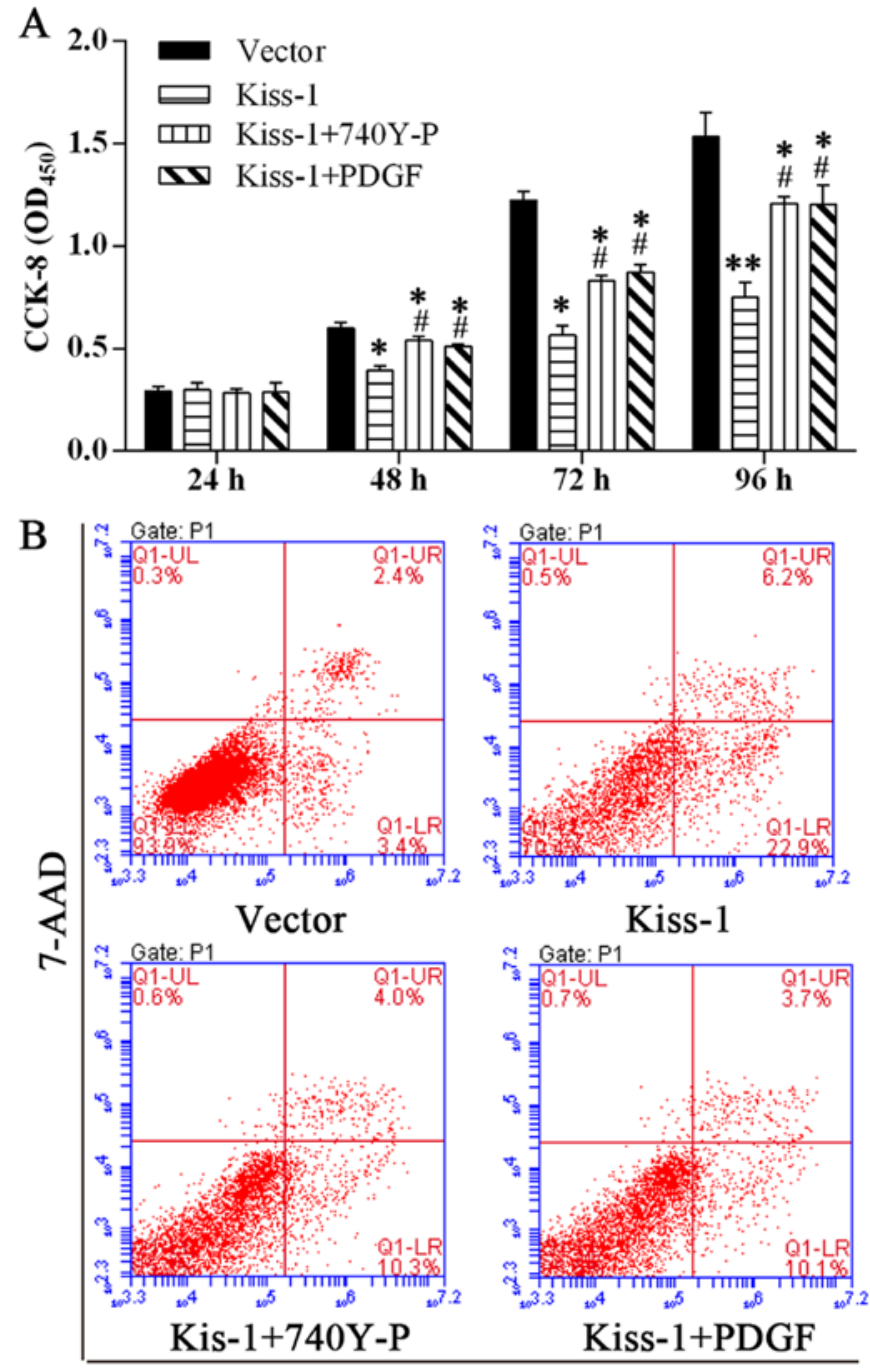

C

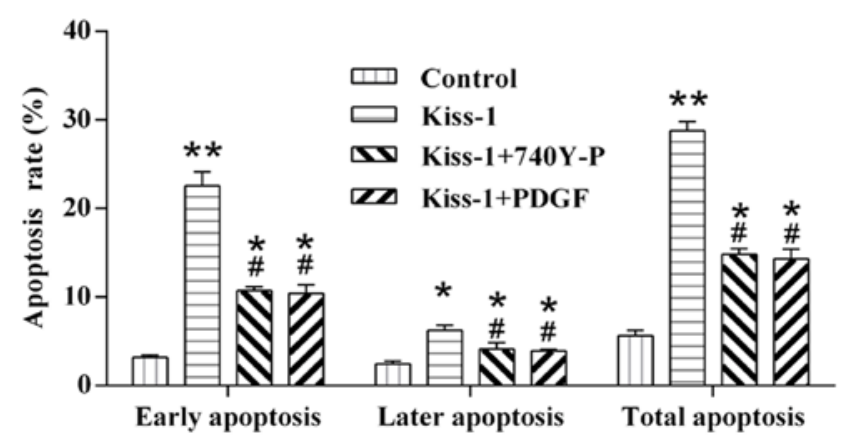

Figure 7. KiSS-1 vector transfection reduces the cell proliferation and apoptosis of HCT-119 cells via PI3K/Akt pathway. (A) Influence of KiSS-1 vector transfection on the cell viability. (B) Influence of KiSS-1 vector transfection on cell apoptosis. (C) Percentage of apoptotic cells illustrated by FACS. Significantly different from vector, ${ }^{*} \mathrm{P}<0.05$. Significantly different from vector, ${ }^{* *} \mathrm{P}<0.01$. Significantly different from Kiss-1 group, ${ }^{\sharp} \mathrm{P}<0.05$.

possible interactions between these processes, we investigated the overexpression of KiSS-1 on the synthesis of PI3K, Akt, pAkt, and NF- $\mathrm{kB}$ subunit p65. Our data showed that upregulation of KiSS-1 was associated with the inhibition of MMP-9, PI3K, pAkt, and p65. The PI3K/Akt and NF- $\mathrm{KB}$ signal transduction pathways are involved in the resistance of numerous solid tumors against a variety of anticancer drugs (23-25).

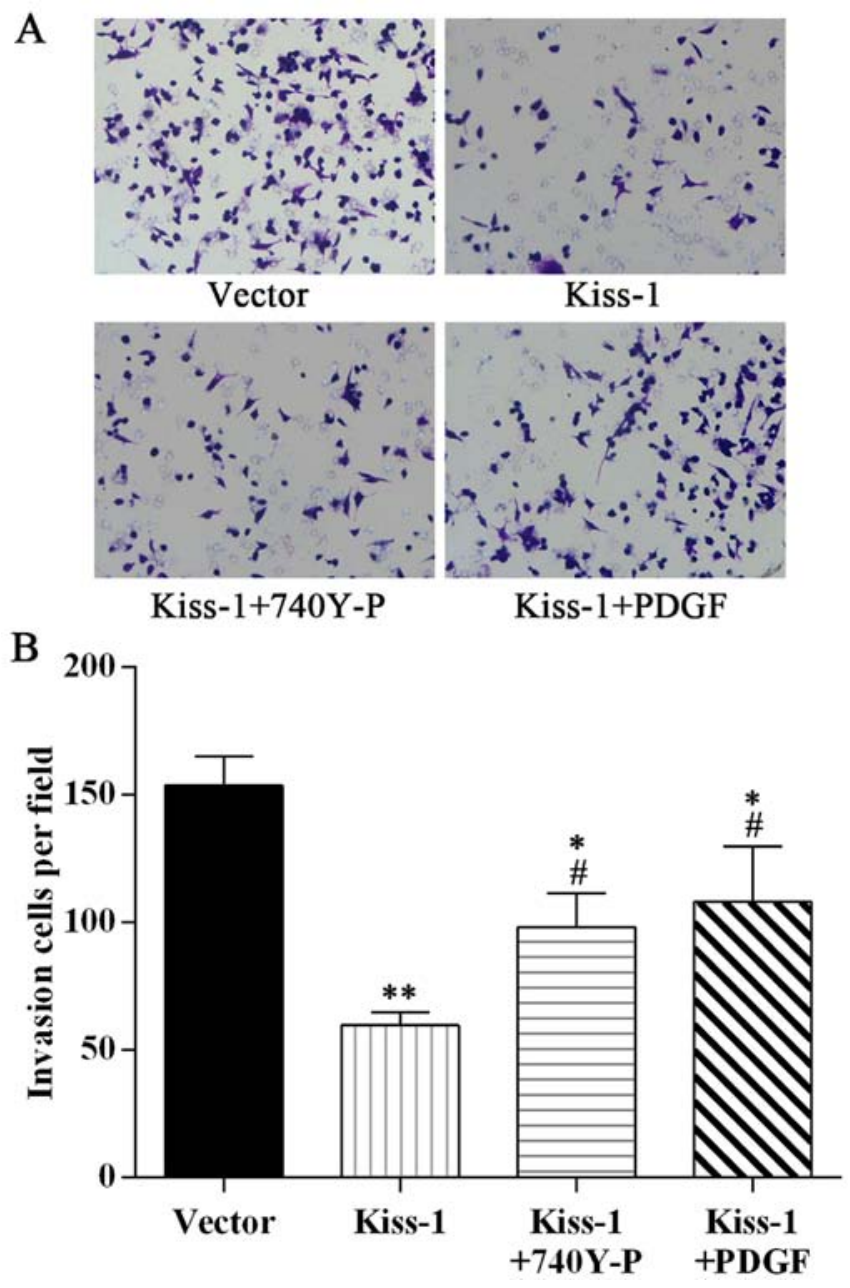

Figure 8. KiSS-1 vector transfection reduces the invasion of HCT-119 cells via PI3K/Akt pathway. (A) The graph represents invasion ability of HCT-119 cells detected by transwell experiments. (B) Influence of KiSS-1 vector transfection on the invasion ability of HCT-119 cells. Significantly different from vector, ${ }^{*} \mathrm{P}<0.05$. Significantly different from vector, ${ }^{* *} \mathrm{P}<0.01$. Significantly different from Kiss-1 group, ${ }^{\#} \mathrm{P}<0.05$.

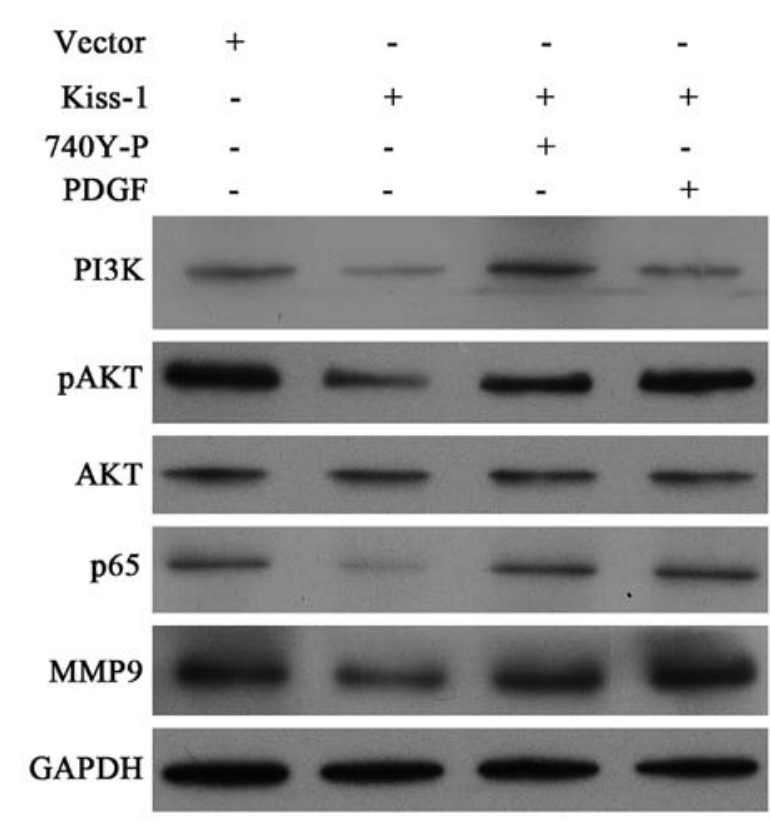

Figure 9. Effect of KiSS-1 protecting against CRC depends on the inhibition of the PI3K/Akt/NF- $\mathrm{KB}$ signal transduction pathway. 
By using array analysis, Agarwal et al (26) found that most genes of $\mathrm{PI} 3 \mathrm{~K} / \mathrm{Akt} / \mathrm{IKB}$ pathway were implicated in tumor angiogenesis and metastasis and positively regulating $\mathrm{NF}-\kappa \mathrm{B}$ and $\beta$-catenin in CRC cells.

In our experiment, we used agonists of PI3K and Akt to further detect the influence of KiSS-1 on this pathway. Both agonists activated the phosphorylation of Akt which was inhibited by the overexpression of $K i S S-1$, and then increased the expression of downstream p65 and MMP-9. However, Akt agonist PDGF had no effect on the expression of PI3K. Considering the regulating function of PI3K on Akt, this result confirmed that regulation of KiSS-1 on this pathway came into play in a PI3K to Akt pattern. Taken all the results together, we come to a conclusion that overexpression of KiSS-1 suppressed the invasiveness of CRC cells, mainly through downregulation of MMP-9 expression mediated by PI3K/Akt/NF- $\mathrm{B}$ signal transduction pathway. This pathway also exits in other cell models: Yan et al demonstrated KiSS-1 could repress MMP-9 via reducing $\mathrm{NF}-\kappa \mathrm{B}$ binding to the MMP-9 promoter and Cheng et al showed that radiation enhanced the expression of MMP-9 via PI3K/Akt/NF-кB $(10,19)$.

Collectively, our data revealed that overexpression of $K i S S-1$ could suppress the invasiveness of CRC cells, and the gene exerted its function by reducing the expression of MMP-9 by block of the PI3K/Akt/NF- $\kappa \mathrm{B}$ pathway. The therapeutic effect of KiSS-1 depends not only on the elimination of local disease, but also on inhibiting systemic dissemination of CRC cells. The clarification of signal transduction mediators involved in this process might facilitate the development of specific inhibitors to modulate CRC metastatic signaling in the clinic.

\section{Acknowledgements}

The present study was supported by the National Key Clinical Specialties Construction Projects and the Key Project of Fujian Science and Technology Department (no. 2014y0021). The funders had no role in the study design, data collection and analysis, or preparation of the manuscript.

\section{References}

1. Meijer G: GLOBOCAN 1: Cancer incidence and mortality worldwide. J Clin Pathol 53: 164, 2000.

2. Wang H, Dwyer-Lindgren L, Lofgren KT, Rajaratnam JK, Marcus JR, Levin-Rector A, Levitz CE, Lopez AD and Murray CJ: Age-specific and sex-specific mortality in 187 countries, 1970-2010: A systematic analysis for the Global Burden of Disease Study 2010. Lancet 380: 2071-2094, 2012.

3. Blanco-Calvo M, Concha Á, Figueroa A, Garrido F and Valladares-Ayerbes M: Colorectal cancer classification and cell heterogeneity: A systems oncology approach. Int J Mol Sci 16: 13610-13632, 2015.

4. Langley RR and Fidler IJ: The seed and soil hypothesis revisited - the role of tumor-stroma interactions in metastasis to different organs. Int J Cancer 128: 2527-2535, 2011.

5. Vogelstein B, Fearon ER, Hamilton SR, Kern SE, Preisinger AC, Leppert M, Nakamura Y, White R, Smits AM and Bos JL: Genetic alterations during colorectal-tumor development. N Engl J Med 319: 525-532, 1988.

6. Zucker S, Lysik RM, Zarrabi MH and Moll U: M(r) 92,000 type IV collagenase is increased in plasma of patients with colon cancer and breast cancer. Cancer Res 53: 140-146, 1993.
7. Onisto M, Garbisa S, Caenazzo C, Freda MP, Di F, Nitti D and Stetler-Stevenson WG: Reverse transcription-polymerase chain reaction phenotyping of metalloproteinases and inhibitors involved in tumor matrix invasion. Diagn Mol Pathol 2: 74-80, 1993.

8. Tutton MG, George ML, Eccles SA, Burton S, Swift RI and Abulafi AM: Use of plasma MMP-2 and MMP-9 levels as a surrogate for tumour expression in colorectal cancer patients. Int J Cancer 107: 541-550, 2003

9. Liabakk NB, Talbot I, Smith RA, Wilkinson K and Balkwill F: Matrix metalloprotease 2 (MMP-2) and matrix metalloprotease 9 (MMP-9) type IV collagenases in colorectal cancer. Cancer Res 56: 190-196, 1996

10. Cheng JC, Chou CH, Kuo ML and Hsieh CY: Radiationenhanced hepatocellular carcinoma cell invasion with MMP-9 expression through PI3K/Akt/NF-kappaB signal transduction pathway. Oncogene 25: 7009-7018, 2006.

11. Lee JH, Miele ME, Hicks DJ, Phillips KK, Trent JM, Weissman BE and Welch DR: KiSS-1, a novel human malignant melanoma metastasis-suppressor gene. J Natl Cancer Inst 88: 1731-1737, 1996.

12. Lee J-H and Welch DR: Suppression of metastasis in human breast carcinoma MDA-MB-435 cells after transfection with the metastasis suppressor gene, KiSS-1. Cancer Res 57: 2384-2387, 1997.

13. Hamid T, Gu Y, Ortines RV, Bhattacharya C, Wang G, Xuan YT and Prabhu SD: Divergent tumor necrosis factor receptor-related remodeling responses in heart failure: Role of nuclear factorkappaB and inflammatory activation. Circulation 119: 1386-1397, 2009.

14. Fearon ER and Vogelstein B: A genetic model for colorectal tumorigenesis. Cell 61: 759-767, 1990.

15. Cunningham D, Atkin W, Lenz HJ, Lynch HT, Minsky B, Nordlinger B and Starling N: Colorectal cancer. Lancet 375: 1030-1047, 2010.

16. Shinto E, Baker K, Tsuda H, Mochizuki H, Ueno H, Matsubara O, Foulkes WD and Jass JR: Tumor buds show reduced expression of laminin-5 gamma 2 chain in DNA mismatch repair deficient colorectal cancer. Dis Colon Rectum 49: 1193-1202, 2006.

17. García-Solano J, Conesa-Zamora P, Trujillo-Santos J, Torres-Moreno D, Mäkinen MJ and Pérez-Guillermo M: Immunohistochemical expression profile of $\beta$-catenin, E-cadherin, P-cadherin, laminin-5 $\gamma 2$ chain, and SMAD4 in colorectal serrated adenocarcinoma. Hum Pathol 43: 1094-1102, 2012.

18. Matrisian LM: Metalloproteinases and their inhibitors in matrix remodeling. Trends Genet 6: 121-125, 1990.

19. Yan C, Wang H and Boyd DD: KiSS-1 represses 92-kDa type IV collagenase expression by down-regulating NF-kappa B binding to the promoter as a consequence of Ikappa Balpha-induced block of p65/p50 nuclear translocation. J Biol Chem 276: 1164-1172, 2001.

20. Criswell T, Leskov K, Miyamoto S, Luo G and Boothman DA: Transcription factors activated in mammalian cells after clinically relevant doses of ionizing radiation. Oncogene 22: 5813-5827, 2003.

21. Dent P, Yacoub A, Contessa J, Caron R, Amorino G, Valerie K, Hagan MP, Grant S and Schmidt-Ullrich R: Stress and radiationinduced activation of multiple intracellular signaling pathways. Radiat Res 159: 283-300, 2003.

22. Ruhul Amin AR, Senga T, Oo ML, Thant AA and Hamaguchi M: Secretion of matrix metalloproteinase- 9 by the proinflammatory cytokine, IL-1beta: a role for the dual signalling pathways, Akt and Erk. Genes Cells 8: 515-523, 2003.

23. Vivanco I and Sawyers CL: The phosphatidylinositol 3-Kinase AKT pathway in human cancer. Nat Rev Cancer 2: 489-501, 2002.

24. Arlt A and Schäfer H: NFkappaB-dependent chemoresistance in solid tumors. Int J Clin Pharmacol Ther 40: 336-347, 2002.

25. Karin M, Cao Y, Greten FR and Li ZW: NF-kappaB in cancer: From innocent bystander to major culprit. Nat Rev Cancer 2: 301-310, 2002.

26. Agarwal A, Das K, Lerner N, Sathe S, Cicek M, Casey G and Sizemore N: The AKT/I kappa B kinase pathway promotes angiogenic/metastatic gene expression in colorectal cancer by activating nuclear factor-kappa B and beta-catenin. Oncogene 24: 1021-1031, 2005. 